\title{
Dinâmicas da agricultura familiar com cultura do dendezeiro no município de Moju, na Amazônia paraense
}

\section{Dynamics of family agriculture with oil palm crops in the municipality of Moju, Amazon region of the state of Pará, Brazil}

\begin{abstract}
João Santos Nabum - Mestre em Planejamento do Desenvolvimento pelo Núcleo de Altos Estudos Amazônicos (NAEA/UFPA). Doutorado em Geografia pela Unesp-Rio Claro. Professor da Faculdade de Geografia e Cartografia e do Programa de Pós-Graduação em Geografia da UFPA. E-mail: prof.joaonahum@gmail.com
\end{abstract}

Cleison Bastos dos Santos - Doutorando pelo Programa de Pós-Graduação em Geografia (PPGEO), da Universidade Federal do Pará. Professor de Geografia da Secretaria Municipal de Educação de Moju e da Secretaria Executiva de Educação do Estado do Pará - 3ª URE. E-mail: cleisongeo@gmail.com

Ana Cláudia Alves de Carvalho - Doutoranda em Geografia pelo Programa de PósGraduação em Geografia (PPGEO), da Universidade Federal do Pará. E-mail: carvalho_ anaclaudia@yahoo.com.br

\section{Resumo}

Analisamos a dinâmica da agricultura familiar do dendê no espaço rural de Moju, estado do Pará. Interpretamos os traços estruturais dessa modalidade produtiva e suas implicações no lugar. Para tanto, revisitamos literatura e legislação concernente ao tema, bem como realizamos trabalho de campo onde entrevistamos produtores, representantes das associações produtoras das comunidades e das empresas integradas a cadeia produtiva. $\mathrm{Na}$ primeira parte caracterizamos em largos traços a expansão da dendeicultura na aurora do século XXI, decorrente do Programa Nacional de Produção e Uso do Biodiesel e Programa de Produção Sustentável de Óleo Programa de Produção Sustentável de Óleo de Palma no Brasil; na segunda os traços gerais dos projetos de agricultura familiar associados às empresas no Moju, destacando-se a experiência da Agropalma.

\section{Palavras-chave}

Agricultura Familiar. Dendeicultura. Amazônia. Agropalma.

\begin{abstract}
We analyzed the dynamics of oil palm family agriculture in the rural area of the municipality of Moju, state of Pará, Brazil. The structural traits of this production modality and their implications in the region were interpreted. To that end, we reviewed the literature and legislation on the subject, besides carrying out field work by interviewing producers and representatives of production associations of the communities and companies involved in the productive chain. In the first part, we characterize in general lines the expansion of oil palm farming in the dawn of the $21 \mathrm{st}$ century caused by the National Program of Biodiesel Production and Use and the Program of Sustainable Palm Oil Production in Brazil. The second part brings an overview of family agriculture projects associated with companies in Moju, in particular the experience of Agropalma.
\end{abstract}

\section{Keywords}

Family Agriculture. Oil Palm Farming. Amazon. Agropalma. 


\section{INTRODUÇÃO}

Interpretamos a chegada da dendeicultura na microrregião de ToméAçu, na Amazônia paraense, tal como um evento reorganizador da paisagem, da configuração territorial, da dinâmica social, enfim do espaço geográfico ou território usado (NAHUM; MALCHER, 2012). Desde então, temos demarcado um período geográfico do dendê (CARVALHO; NAHUM, 2014), possibilitado por pesquisas acerca das condições edafoclimáticas necessárias e propícias ao cultivo em grande escala da palma do dendê; por um conjunto de ações governamentais tais como o Plano Nacional de Produção e Uso de Biodiesel (PNPB) e o Programa de Produção Sustentável de Óleo de Palma no Brasil (PPSOP) que propõem alternativas à matriz energética alicerçada no combustível fóssil e integrar o agricultor camponês à cadeia produtiva do agronegócio na Amazônia; por fim, estimulado pela voracidade do mercado de commodities de óleo de palma, que encontrou seus limites físicos e territoriais no continente asiático, por isso expande-se para África e América Latina.

É grande a rentabilidade produtiva do dendezeiro (Elaeis guineensis Jacq) comparada com outras oleaginosas. Essa palma possui a maior produtividade, com rendimento entre 4 a 6 toneladas de óleo/ha/ano, correspondendo a 1,5 vezes a produtividade do óleo de coco, a 2 vezes a do óleo de oliva e mais do que 10 vezes a do óleo de soja, superado apenas pelas algas, que tem produtividade anual entre 50 a 150 toneladas por hectares (SILVA, 2015). A produção dos cachos tem início a partir dos 3,5 anos após o plantio, chegando ao ápice entre 7 e 15 anos. Do ponto de vista econômico sua vida útil é de 25 anos, com rendimentos superiores a 25-28 toneladas de cachos por ha/ano. Dois tipos de óleo são extraídos dos frutos da palma, sendo o mais valioso o do palmiste, proveniente da amêndoa ou endosperma e o produto comum é o óleo decorrente do esmagamento da polpa ou mesocarpo (RIVAL; LEVANG, 2014).

Teses, dissertações, publicações especializadas, jornais, dentre outros, em uníssono exaltam as virtudes da palma africana que prodigiosamente tão bem se adaptou ao solo amazônico. Sublinham que seu cultivo seria capaz de promover o desenvolvimento sustentável, recuperando ambientalmente, economicamente e socialmente áreas degradas pela pecuária. O cultivo do dendezeiro geraria empregos e renda para o agricultor familiar, que não terminaria seus dias praticando cultivos de pouco rendimento econômico. Este, dada sua disposição para o trabalho, organização familiar e a baixa escolaridade poderia ser absorvido para trabalhar nos campos de dendezeiro, seja na produção direta em sua propriedade ou nas empresas (FURLAN JÚNIOR et al., 2006; CASTRO; LIMA; SILVA, 2010; 
SUFRAMA/FGV, 2003; SILVA, 2006; SEMEDO, 2006; EMBRAPA, 2006). No entanto, tão importante quanto ressaltar as potencialidades econômicas, ambientais e sociais do dendezeiro, é compreender sobre as metamorfoses no modo de vida do lugar onde esse agronegócio se expande.

Centramos a análise sobre um aspecto comum nos lugares onde se estabelece a monocultura, qual seja, o que significa para o agricultor familiar tornarse produtor de dendê. Analisamos as relações entre dendeicultura e agricultura familiar no município de Moju, estado do Pará, a partir do projeto de produção familiar criado pela associação entre o Estado brasileiro e capital nacional e internacional. Para tanto, revisitamos literatura e legislação concernente ao tema, bem como realizamos trabalho de campo onde entrevistamos produtores, representantes das associações produtoras das comunidades e das empresas integradas a cadeia produtiva. A situação geográfica em foco é o espaço rural de Moju, berço da dendeicultura empresarial, onde ela é mais dinâmica e diversificada. Dentre as empresas, normas e unidades produtoras familiares de dendezeiro, privilegiamos a prática do Grupo Agropalma, por ser pioneiro no processo, com experiência de 16 anos e um nível de enraizamento e abrangência amplo; sendo protótipo para os projetos de empresas como Marborges S.A., Biopalma S.A. e Belém Brasil Bioenergia S.A. Na primeira parte caracterizamos em largos traços a expansão da dendeicultura na aurora do século XXI, decorrente do Programa Nacional de Produção e Uso do Biodiesel e Programa de Produção Sustentável de Óleo Palma no Brasil; na segunda discorremos sobre os projetos de agricultura familiar de dendezeiro associados às empresas no Moju, destacando-se aqueles associados a Agropalma.

\section{O TERRITÓRIO PARA O DENDÊ}

O espaço rural da Amazônia paraense é marcado pela dendeicultura (NAHUM; SANTOS, 2013), cuja dinâmica deve ser entendida a partir de um processo de reorganização da matriz energética europeia, que tem por meta desenvolver fontes alternativas às fósseis (ALTVATER, 2010; GIDDENS, 2010; HOUTART, 2010). Segundo Lima e Castro (2010, p. 50), “a Comunidade Europeia (ou União Europeia) é o maior produtor mundial de biodiesel e tem apresentado uma posição bastante firme na substituição de combustíveis fósseis por fontes renováveis, em sua matriz energética". A divisão internacional do trabalho configura um circuito global de produção de matéria-prima para o biodiesel, que tem na Ásia, na África e na América Latina áreas privilegiadas nisso. Mas é por meio do Plano Nacional de Produção de Uso do Biodiesel, lançado em 
2004, que o Estado brasileiro propõe política para o biodiesel, criando condições financeiras e normativas para expansão da palma africana no trópico úmido.

$\mathrm{Na}$ década de 1980, o município de Moju foi o primeiro a ter empreendimento voltado para a dendeicultura, referimo-nos a extinta Reflorestadora da Amazônia S.A. (REASA). A dendeicultura desde então se expande nos municípios de Acará, Moju, Tailândia, Tomé-Açu e Concórdia do Pará, pertencentes à microrregião de Tomé-Açu, no estado do Pará, onde a cadeia produtiva do dendezeiro é mais estruturada. A chegada das empresas Amapalma, na década de 1990, Guanfeng e Biopalma, em 2009 e 2010 respectivamente, e da Belém Brasil Bioenergia (BBB), em 2011, colocaram Moju, segundo os dados oficiais do Instituto Brasileiro de Geografia e Estatística, na terceira posição em quantidade produzida de Cachos de Frutos Frescos (CFF) no estado do Pará, com 141.151 toneladas, atrás apenas do município de Acará, com 195.000 toneladas, e de Tailândia, com 405.055 toneladas ${ }^{1}$.

O Zoneamento Agroecológico do Dendezeiro para as Áreas Desmatadas da Amazônia Legal (EMBRAPA, 2010) e o Decreto nำ 7.172, de 7 de maio de 2010, que aprova o zoneamento agroecológico da cultura da palma de óleo, identificaram no Moju, entre áreas preferenciais e regulares para o cultivo do dendê, 4.012,69 km²; aproximadamente 44\% do total do município, que, segundo o IBGE, é de $9.094,135 \mathrm{~km}^{2}$. Sob os pilares da técnica e da ação política reedita-se a ideologia do espaço vazio, tal como na época dos Planos de Desenvolvimento da Amazônia (NAHUM, 2012), áreas antropizadas e subaproveitadas economicamente, propícias às frentes de expansão do dendê.

Em relação à mão-de-obra, a expansão da dendeicultura encontra apoio e cumplicidade do sindicato dos trabalhadores rurais, das secretarias municipal e estadual de agricultura, bem como da federação dos trabalhadores na agricultura do estado do Pará. Além do que, a histórica simbiose entre movimentos sociais e partidos políticos acentuada no início do século XXI, fez com que muitas lideranças dos movimentos sociais no campo na Amazônia se elegessem vereador, deputado, senador, secretário de estado ou fossem incorporadas em alguma parte do organograma governamental e reproduzissem essa política de estado, o que silenciou qualquer discurso alternativo, crítico ou contestatório à dendeicultura como vetor do desenvolvimento territorial rural. Estão dadas, portanto, as condições políticas para a emergência da monocultura como pensamento único, espécie de discurso competente, lacunar (CHAUÍ, 1990), mas atacando problemas históricos da agricultura familiar, quais sejam, custear, produzir, distribuir e comercializar a preço de mercado. Isso é claro no Decreto n⿳⺈ 5.297,

Disponível em: https://cidades.ibge.gov.br/. Acesso em: 02 mar. 2018. 
de 6 de dezembro de 2004, onde no Art. $2^{\circ}$ fica instituído o selo "Combustível Social", que será concedido ao produtor de biodiesel que:

I - promover a inclusão social dos agricultores familiares enquadrados no Programa Nacional de Fortalecimento da Agricultura Familiar - PRONAF, que lhe forneçam matéria-prima; e

II - comprovar regularidade perante o Sistema de Cadastramento Unificado de Fornecedores - SICAF.

$\int 1^{\circ}$ Para promover a inclusão social dos agricultores familiares, o produtor de biodiesel deve:

I - adquirir de agricultor familiar, em parcela não inferior a percentual a ser definido pelo Ministério do Desenvolvimento Agrário, matéria-prima para a produção de biodiesel;

II - celebrar contratos com os agricultores familiares, especificando as condições comerciais que garantam renda e prazos compatíveis com a atividade, conforme requisitos a serem estabelecidos pelo Ministério do Desenvolvimento Agrário; e

III - assegurar assistência e capacitação técnica aos agricultores familiares (BRASIL, 2004).

Enquanto discurso competente (CHAUÍ, 1990), a expansão dos dendezais aparece como exemplo de paradigma do capitalismo agrário capaz de promover o agricultor tradicional à condição de empreendedor familiar, nos moldes europeus (ABRAMOVAY, 2012). Reedita-se a ideologia da fronteira, bem como a representação de Amazônia como fronteira agrícola (LÉNA; OLIVEIRA, 1992; D'INCAO, OLIVEIRA, 1994; AUBERTIN, 1988; MARTINS, 1997; CARDOSO, MULLER, 2008; NAHUM, 2012). Em 2004, tínhamos o dendezeiro cultivado pela "Agropalma, Marborges, Dentaua e Palmasa restringiam-se aos municípios de Moju, Acará, Tailândia, Santo Antônio do Tauá e Igarapé-Açu” (NAHUM; SANTOS, 2015, p. 2). Segundo dados da EMBRAPA², a área colhida de dendê no Brasil que em 2004 era de 87.542 mil/ha, em 2016 expande-se para $142.246 \mathrm{mil} / \mathrm{ha}$, aproximadamente $61,5 \%$.

Ainda segundo a EMBRAPA, em 2004, o Pará tinha $45.96 \mathrm{mil} / \mathrm{ha}$ de dendezeiro, em 2016 são 99,4 mil/ha, aproximadamente 46,2\%. Em 2017 essa atividade era desenvolvida pela Biopalma, Archer Daniels Midland (ADM), Agropalma, Denpasa, Dentaua, Marborges, Yossan, Palmasa, Guanfeng do Brasil, Belém Bioenergia Brasil, dentre outras, distribuídas pelos municípios de Abaetetuba, Acará, Aurora do Pará, Baião, Bujaru, Cametá, Castanhal, Capitão Poço, Concórdia do Pará, Garrafão do Norte, Igarapé-Açu, Irituia, Mãe do rio, Mocajuba, Moju, São Domingos do Capim, Tailândia e Tomé-Açu (Figura 1).

2 Disponível em: https://www.embrapa.br/agropensa/producao-agricola-municipal. Acesso em: 04 mar.2018. 
Figura 1 - Empresas dendeicultoras em município do estado do Pará em 2017

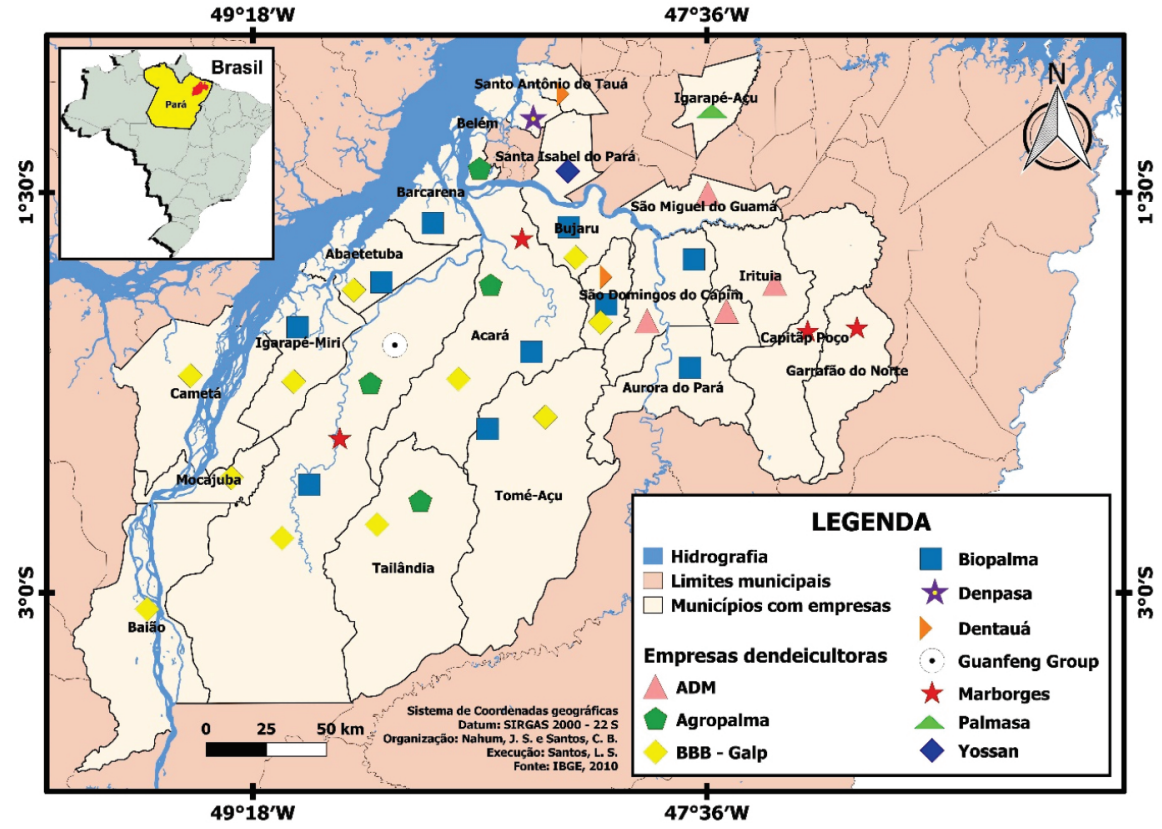

Fonte: IBGE, organizado pelo Grupo de Pesquisa Dinâmicas Territoriais do Espaço Rural na Amazônia (GDEA).

Neste período formam-se territórios do dendê possibilitados por políticas estatais associadas aos interesses empresariais. De modo que os dendezais das empresas constituem um recurso por meio do qual reinventam as condições materiais de existência dos lugares sob sua influência. $\mathrm{O}$ tamanho e quantidade dos pontos dependem da envergadura e natureza do capital acionado para transformar extensas terras em território do dendê. Todavia, nem toda empresa de dendê tem condições políticas, econômicas e espaciais para construir seu território-rede (NAHUM; SANTOS, 2013). No estado do Pará conhecemos quatro caminhos pelos quais as empresas adquirem terra e produzem o dendê: compra, arrendamento, associação com produtor familiar e aquisição da produção de produtores particulares. Tem prevalecido a aquisição por compra de áreas antropizadas predominantemente, mas não somente, pela extração de madeira, precursora da pecuária extensiva e de fazenda que tem na renda da terra seu principal instrumento de valorização. Somente na microrregião de Tomé-Açu, no nordeste paraense, a Biopalma tem 87 propriedades no seu nome, abrangendo mais de 134 mil hectares, onze no Moju. 
No Moju, na modalidade arrendamento temos 510 hectares do Sr. Altino Coelho, arrendados pela Agropalma; além das fazendas Vitória, com 705 hectares, e Primavera, com 810 hectares arrendadas pela Belém Brasil Bioenergia. As empresas pagam ao proprietário pelo uso de suas terras para cultivar o dendezeiro, geralmente os contratos são de 25 anos, período de vida econômica útil da palma. Ratifica-se, desse modo, na Amazônia paraense do século XXI a renda da terra, "considerada como preço pago pelo usa da terra", tal como exposta por Smith (1996, p. 185), no século XVIII. Na modalidade produtores independentes de dendê, que vende a produção para as empresas, temos as propriedades dos senhores Domingos Lima, com 34 hectares, Hitofume Kimura, com 580, e José Wanderley, com 2.221, totalizando 2.835 hectares. Quanto às áreas de plantio próprio, temos a Marborges, com 6.250 hectares, a Biopalma, com 9.328, e a Agropalma, com 4.954 (SANTOS, 2015).

\section{A AGRICULTURA FAMILIAR DE DENDÊ}

Os agricultores familiares a que nos referimos são proprietários ou não da terra que dedicam 10 hectares à produção de dendê seguindo acordo contratual da empresa e sob financiamento do Banco da Amazônia S.A. A Marborges, a Agropalma, a Belém Brasil Bioenergia e a Biopalma são empresas que desenvolvem projetos de agricultura familiar de dendê. Segundo os dados levantados na pesquisa, a modalidade soma 266 famílias, sendo cinco projetos associados com a Marborges; 155 com a Agropalma; e 106 com a Biopalma, totalizando 2.660 hectares de plantio de dendê. Quanto aos projetos integrados à Belém Bioenergia, segundo o setor agrícola da empresa, há em Moju 181 projetos familiares com dimensões de 7, 8, 9 e 10 hectares.

A comunidade do Arauaí é englobada pela dinâmica do dendezeiro no ano de 2002, quando o Grupo Agropalma, a prefeitura Municipal de Moju, o Instituto de Terras do Estado do Pará (ITERPA), a Empresa de Assistência Técnica e Extensão Rural (EMATER), a Secretaria de Agricultura do estado do Pará (SAGRI), o Banco da Amazônia S.A. (BASA) juntamente com os colonos da comunidade, implantaram o pioneiro "Projeto de Agricultura Familiar com Cultura de Dendê".

Segundo o responsável pela implantação do projeto de agricultura familiar, em entrevista concedida a Cruz (2006, p. 127), "a motivação que levou a empresa a estabelecer essa parceria com os pequenos produtores foi a preocupação com as populações ribeirinhas que vivem próximas as áreas de projeto da empresa". No entanto, ainda segundo o autor, em entrevista com o responsável da SAGRI 
no projeto de agricultura familiar, este informou que "o projeto já vinha sendo desenvolvido pelo Governo do Estado do Pará no município de Concórdia do Pará, mas devido a uma série de problemas foi abandonado, daí surgindo à necessidade desenvolvê-lo em outro local" (CRUZ, 2006, p. 127-129). Foi dentro deste contexto, que a Agropalma se interessou e criou condições para implantação do projeto piloto no município de Moju.

O projeto foi pensado em três etapas e envolveu agricultores que criavam, cultivavam, extraíam e produziam tão somente para reprodução da unidade produtiva familiar. O projeto de agricultura familiar do dendê forma-se quando o Estado cria um projeto de assentamento destinado ao cultivo da palma, a empresa proporciona o saber/fazer da cultura do dendê, o Banco disponibiliza linha de crédito e o agricultor entra com força de trabalho. Tudo pensado para a dendeicultura se constituir renda complementar às atividades tradicionais desenvolvidas nos sítios.

A primeira iniciou em 2002, na comunidade do Arauaí, com o plantio de 500 hectares, distribuídos em lotes de 10 hectares para cada família, num total de 50 famílias. A segunda, em 2004, na comunidade da Soledade, também localizada no alto Moju, com 500 hectares destinados para 50 famílias e a terceira, no ano de 2005, novamente na Comunidade do Arauaí, denominado Arauaí II, com o plantio de 500 hectares, distribuído em lotes de 10 hectares destinados para 50 famílias. Totalizando 1.500 hectares para 150 famílias. O projeto foi estendido, em 2006, para o Projeto de Assentamento, Calmaria II, do Instituto de Colonização e Reforma Agrária (INCRA), localizado nas proximidades do km 65, da rodovia PA-150, com uma área de 210 hectares destinados para 35 famílias, cada uma com 6 hectares (BASA, 2012).

Os agricultores dos projetos I e III da comunidade do Arauaí trabalham na terra na condição de assentados da reforma agrária, que tem a titulação coletiva, isto é, podem usar a terra, mas não tem a titulação individual da mesma. Isso foi possível quando, segundo Pinto et al. (2009):

O governo do estado do Pará através do Decreto no 1.198 , de 23 de agosto de 2004, em seu Art. 1ㅜ, considerando entre outras coisas, que compete ao poder público estimular os empreendimentos idôneos e contribuir para o desenvolvimento econômico e social da região, reserva à Associação do Desenvolvimento Econômico do Ramal do Arauaí, uma área de terras medindo 2.714 ha 23 a e $96 \mathrm{ca}$ (dois mil e catorze hectares, vinte e três ares e noventa e seis cantares). No Art. $2^{\circ}$ diz que "a área de terras previstas no Art. $1^{\circ}$ não poderá ser objeto de qualquer operação que importe na sua transferência a terceiros, sob qualquer hipótese", portanto a área foi doada à Associação, sendo que cada lote seria "arrendado" as famílias 
participantes do projeto para utilizarem 10 hectares com dendê. Sendo que, caso alguma família abandonasse ou não tratasse o lote corretamente de acordo com as recomendações agronômicas do profissional responsável pela área, o mesmo poderá ser repassado para outra família que tenha interesse em assumir a atividade e o financiamento bancário, fato que ocorreu com apenas 6\% (seis por cento) dos lotes durante os 8 (oito) anos de existência do projeto I (PINTO et al., 2009, p. 32).

Inicialmente o projeto organizou-se de modo a cada família receber 10 hectares para cultivar 160 plantas por hectare, somando 1.600 plantas por lote e, mais 2 hectares, um para construção de estrada e outro para plantio de subsistência. A área destinada à cultura de subsistência, posteriormente, não foi incentivada pela empresa, o que causou desconfiança dos agricultores. Isso porque a família envolvia-se desde o começo no preparo dos lotes, mas a palma começa a produzir no terceiro ano. Neste hiato de tempo entre plantio/colheita/ venda os agricultores temiam pelo sustento da família, o que lhes causavam apreensão e desconfiança.

Isso foi sanado por meio do crédito viabilizado pelo Banco da Amazônia que repassou o financiamento do Programa Nacional de Fortalecimento da Agricultura Familiar (PRONAF), concedendo linha de crédito às famílias no valor de $\mathrm{R} \$ 16.107,18$, com juros de 3\% ao ano, carência de três anos e desconto de $40 \%$ da dívida se fosse paga até o dia do vencimento. Dentro do financiamento, foi garantido aos participantes do projeto o valor de 2 dois salários mínimo (cujo valor do salário em 2004 era de $\mathrm{R} \$ 260,00$ ) a cada dois meses durante os três primeiros anos para custear o sustento da atividade até o início da produção dos cachos. Estamos diante de uma linha de crédito precursora do PRONAF-Eco, em 2010, comum aos projetos do dendê que se desenvolvem a partir do Plano Nacional de Produção e Uso do Biodiesel.

O Grupo Agropalma atua no projeto fornecendo as mudas do dendezeiro e proporcionando a infraestrutura inicial para o lote, bem como assistência técnica. Por meio de contrato, a empresa compromete-se a comprar a produção por um período de 25 anos, tempo economicamente útil do dendezeiro, fixando o valor em 10\% do preço Free On Board (FOB) do óleo bruto no porto de Roterdã. Ainda financia os fertilizantes utilizados pelos agricultores num total de $\mathrm{R} \$ 7.000,00$ ao ano, sendo descontados $25 \%$, desse valor, do que o agricultor tem a receber da matéria-prima entregue à empresa; também são descontados 25\% do valor do cultivo do agricultor para ressarcimento do financiamento bancário, introduzido para reduzir o risco de inadimplência do financiamento. 
As obrigações dos produtores são basicamente duas: a) a venda de toda a produção para a empresa durante os 25 anos estabelecidos no contrato; b) os tratos culturais, ou seja, a gestão do plantio. Os primeiros três anos do plantio exigem tratos culturais intensivos como, por exemplo, o coroamento (rebaixo) uma vez por ano, que consiste em eliminar a vegetação que circunda a palma, evitando a competição com as mesmas; a podagem, consiste na retirada de folhas não saudáveis ou danificadas na planta uma vez por ano; a adubação duas vezes ao ano por conta da especificidade do solo amazônico e a aplicação de herbicida uma vez ao ano para as prevenções e os combates das pragas e outras doenças que acometem o dendezeiro (MÜLLER, 1980). O período de colheita do fruto abrange em média 17 dias de trabalho por mês, dado que a palma de dendê produz todos os meses do ano, tendo uma diminuição de produtividade no período do verão.

Os agricultores devem seguir as normas estabelecidas no contrato pela empresa, e caso descumpram alguma cláusula, podem sofrer sanções do grupo. Os agricultores que conseguem desempenhar bons tratos culturais, ou seja, uma boa gestão dos plantios é acrescida $8 \%$ sobre o valor pago pela tonelada. Segundo Alves (2008), quem atrasar a colheita por 60 dias, as atividades de poda e roçagem por mais de 12 meses ou a adubação por mais de 30 dias terá seu contrato cancelado.

O projeto desenvolvido na comunidade do Arauaí seguiu a racionalidade empresarial globalizada da Agropalma onde, segundo Santos (2006):

cada gesto e cada resultado deve se previsto de modo a assegurar a maior produtividade e a maior rentabilidade possível [...] as técnicas a serviço da produção, da armazenagem, do transporte da transformação dos produtos e da sua distribuição, respondem ao modelo mundial e são calcadas em objetivos pragmáticos, tanto mais provavelmente alcançados, quanto mais claro for o cálculo na escola e na sua implantação. É desse modo que se produzem nexos estranhos à sociedade local [...] (SANTOS, 2006, p. 304-305).

A presença da monocultura e a introdução do mesmo ritmo de produção empresarial, ampliou a carga de trabalho dos agricultores familiares, que além da gestão dos lotes de dendê, precisam reservar tempo para os cultivos de subsistência nos sítios (NAHUM; SANTOS, 2017). Para Pinto et al. (2009), a diversidade do tamanho e composição familiar da comunidade pode ocasionar o sobretrabalho e/ ou a contratação de trabalho assalariada:

No projeto encontramos discrepância entre as famílias, por exemplo, uma composta por somente uma pessoa - o produtor - trabalhando quase que 
diariamente para manter o lote produtivo. Outras compostas por 9 (nove) membros, sendo que destes, 6 (seis) trabalham rotineiramente. $\mathrm{O}$ fato de algumas serem pequenas e contarem com pouca mão de obra no período de safra, acarreta na contratação de trabalhadores diaristas (PINTO et al., 2009, p. 36).

A quantidade de frutos frescos colhidos é determinada principalmente pelo tamanho e a composição da família e, o mais importante, pela intensidade do trabalho. No caso da unidade familiar onde há falta de braços disponíveis para movimentar a lavoura isso é solucionado com a ajuda de parentes ou de vizinhos da comunidade. Fizemos um trabalho de campo em março de 2016 na comunidade e de dezesseis famílias entrevistadas, apenas duas disseram ter trabalhado com mutirão no lote. A quase ausência dessa característica da agricultura camponesa se explica pela preocupação que as famílias têm em cumprir os tratos culturais estabelecidos pela empresa, visto que nos três projetos há cinco técnicos fiscalizando diariamente o trabalho dos agricultores.

Do exposto acima, temos um cenário propício para a introdução da mão-de-obra assalariada nos lotes dos produtores. A contratação de trabalho assalariado reduz o ganho da família produtora, pois são contratados em média dois trabalhadores por lote. A contratação explicar-se em função: a) do receio na aplicação dos produtos químicos nas 1.600 plantas de um lote; b) da família numerosa, mas com filhos ainda em fase escolar; c) da família relativamente numerosa, mas com filhos que não possuem habilidade suficiente para desempenhar as tarefas com rapidez necessária; e c) de famílias com poucos filhos. Assim, o que define a entrada do trabalho assalariado no interior da unidade produtiva é a quantidade de braços familiares disponíveis ao cultivo do dendezeiro.

O projeto gerou empregos e aumentou a renda dos agricultores familiares da comunidade. No ano de 2011 os produtores do projeto I receberam pela venda de sua produção, uma receita total de $\mathrm{R} \$ 2.656 .640,00$ equivalente a uma renda anual de $\mathrm{R} \$ 53.132,80$ por família, ou seja, $\mathrm{R} \$ 4.427,73$ por família, aqui faltam os descontos nos insumos, equipamentos e outros (BASA, 2012). Assim, puderam adquirir bens que outrora não possuíam, por exemplo, motos, televisores, geladeiras, e outros eletroeletrônicos. Outra mudança diz respeito ao tipo da moradia e da escola, que no passado na sua maioria eram de madeira, atualmente, são erguidas de alvenaria.

No entanto, nem todos os participantes do projeto conseguem conciliar o trabalho nos lotes de dendezal com a manutenção de suas propriedades, os sítios, como nos explica “seu” Jefith Abreu, do Projeto I: "Muitos de nós abandonemos 
nossos plantios, ficamos quase que exclusivo no dendê. Porque é muito serviço" ("Seu" Jefith, em entrevista pessoal, em 17 de setembro de 2013). esta dificuldade foi confirmada por “dona” Maria, em entrevista ao Repórter Brasil (2010):

Quando eles trazem o adubo, temos obrigação de aplicar. Se não fizer o que eles mandam, se não passar veneno ou podar, eles seguram o nosso dinheiro no banco. Aqui tem cinco fiscais (técnicos da empresa) que ficam controlando tudo", diz a agricultora. Sua família é uma das que não mantiveram as roças de culturas alimentares "porque não dá para fazer as duas coisas ao mesmo tempo (REPÓRTER BRASIL, 2010, p. 20).

No contexto do PNPB foram implantados dois novos projetos de dendê familiar no município de Moju, o Projeto III, também conhecido como Arauaí II, em 2005, e o Projeto Dendê Familiar IV, localizado no Projeto de Assentamento Calmaria II, na comunidade Água Preta, em 2006. A comunidade do Arauaí recebe pela segunda vez o Projeto Agricultura Familiar com Dendê III. Ele foi configurado na comunidade em 2005, abrangendo 50 famílias com 10 hectares de dendezeiros financiados na linha de crédito Pronaf D, sendo destinado para cada família cerca de $\mathrm{R} \$ 26.864,76$ (BASA, 2012).

O Projeto Dendê Familiar IV foi introduzido nos lotes dos assentados do Projeto de Assentamento Calmaria II, em 2006. O PA Calmaria II está localizado nas proximidades do quilômetro 65, da PA-150, na comunidade Água Preta, destinado a 35 famílias, cada uma com seis hectares. A linha de financiamento foi o FNO/Pronaf A. As 35 famílias receberam recursos na ordem de $\mathrm{R} \$ 12.255,75$. O prazo total foi de 10 anos com carência de cinco anos e juros de 1,5\% a.a. As instituições envolvidas no projeto foram a FETAGRI, o Sindicato dos Trabalhadores Rurais de Moju e entidades associativas do PA Calmaria II, o INCRA-PA, o MDA/PA, a SECTAM (hoje SEMA), o IBAMA, o BASA e o Grupo Agropalma (BASA, 2012; INCRA).

A empresa Agropalma, no ano de 2013, acrescentou mais nove projetos, sendo cinco no Arauaí, em Moju, e quatro no PA Calmaria II, no Acará. O PA Calmaria II possui $70 \%$ do seu território no município de Acará e 30\%, em Moju. A pesquisa apontou, com base em dados da EMATER, que os plantios dos assentados não se localizam em Moju, mas no Acará. Desse modo, há uma diferença entre o território jurídico, ou seja, a área de localização do plantio e o território do dendê, que corresponde ao território pertencente ou controlado pelas empresas. Atualmente, as áreas de plantio de dendezeiro na modalidade familiar vinculado ao Grupo Agropalma estão localizadas em dois municípios. No total, são 192 famílias, sendo 35 trabalhando 6 hectares no Projeto de Assentamento Calmaria II no município de Acará, totalizando 210 hectares, e 
157 famílias manejam 10 hectares cada uma, perfazendo 1.570 hectares, na região do Alto Moju, no município de Moju, perfazendo, 1.780 hectares plantados com a cultura do dendezeiro na modalidade familiar.

$\mathrm{Na}$ agricultura familiar do dendê a terra e o trabalho são comandados por determinações do capital. A unidade produtiva inserida nos programas tem a possibilidade de cultivar dendê consorciado com mandioca, melancia, feijão, por exemplo, mas somente no primeiro ano de plantio da palma, quando as raízes ainda não estão completamente desenvolvidas e permite o plantio de culturas que não são de raízes profundas. Entretanto, provavelmente, faltaria energia física ao agricultor para essas atividades, visto que a mesma foi utilizada no empreendimento do dendê. Assim, a pluriatividade característica da unidade familiar camponesa, provavelmente, tende a ceder espaço para a especialização produtiva, predominando o que Bernstein (2011) chama de mercantilização da sobrevivência, ou seja, "[a] mercantilização é o processo pelo qual os elementos de produção e reprodução social são produzidos para troca no mercado e nele obtidos e que os sujeita às suas disciplinas e compulsões" (BERNSTEIN, 2011, p. 125).

Esse projeto exemplifica a apropriação do território pelo capital dendeicultor, sem apropriação da terra, nem contratação de força de trabalho. Melhor que isso, ele usa terra e força de trabalho alheios, condição criada pela política de estado que cede terra aos agricultores, desde que numa parte dela eles cultive dendê. O estado, por meio do PRONAF Eco e do Banco da Amazônia S.A., estabelece as condições normativas e creditícias para financiamento dos recursos. E a empresa tem a gestão do território, isto é, regula seus usos por meio da equação tempo, trabalho e ciclo da cultura do dendê, emergindo uma rotina de trabalho que desconsidera o modo de vida do lugar.

As unidades familiares associadas aos projetos de agricultura familiar de dendê não perdem a propriedade jurídica da terra, tampouco as pessoas tornam-se assalariados das empresas; em suma, continuam proprietárias da terra enquanto meio de produção e força produtiva e sua força de trabalho não é vendida à empresa. Porém, quem determina e comanda os usos dessa terra são as empresas; a terra, por meio de contratos entre partes juridicamente iguais e em comum acordo, transformou-se em território usado pelo dendê. Igualmente a força de trabalho de todos que adentram os campos é treinada, comandada e utilizada exclusivamente para a cultura da palma africana. Portanto, o território usado, isto é, a área e seus usos, são utilizados na reprodução do capital dendeicultor, sobretudo quando assinam contrato com o Grupo Agropalma e com o banco. Cria-se, por esse meio, laço de dependência territorial entre os projetos de agricultura familiar, a empresa e o banco, posto que, não é apenas a 
agroindústria do dendê que expropria os rendimentos dos camponeses o capital financeiro também o faz pela dependência destes ao crédito bancário e seu constante endividamento.

Ainda que tenhamos agricultores familiares trabalhando com o dendê, isso não é suficiente para afirmar que o trabalho na cultura e processamento do dendê foi o que lhes atraiu; não induz a afirmar que a segurança salarial oferecida pelas empresas dendeicultoras atrai os agricultores tradicionais. O processo é mais complicado. Compreendemos que não é o projeto de agricultura familiar do dendê o que atrai os agricultores camponeses, mas a ausência de política de estado para as comunidades rurais camponesas direciona o agricultor camponês para reprodução de um modo de vida que não é o seu (NAHUM; BASTOS, 2014). Senão vejamos, o agricultor tradicional não dispõe de alternativa produtiva com o mesmo suporte institucional capaz de se configurar como alternativa ao dendê. Nenhuma linha do PRONAF recebe tanto apoio e incentivo do Estado e do capital quanto o PRONAF ECO, sobretudo no que se refere a garantia de compra do produto a preço de mercado e monitoramento de todas as fases do processo produtivo, a começar pelo piqueteamento da área, treinamento para coleta e mesmo carregamento da produção até a agroindústria. Mesmo as organizações representativas dos camponeses, agricultores familiares e trabalhadores rurais carecem de propostas alternativas à dendeicultura enquanto pensamento único para o desenvolvimento rural, geração de emprego e renda. Movimentam-se no mesmo campo político que reivindica a inclusão da agricultura familiar nos projetos de dendê como única política de estado para o meio rural. Portanto, assistimos, isto sim, a continuidade de um longo processo de formação de um campo sem camponeses, lentamente gestado por um Estado que secundariza política agrária que prime pela reprodução do modo de vida do campesinato tradicional.

As políticas propostas até aqui são desenvolvimentistas e produtivistas, concebem o campo como um espaço econômico, um espaço para produção e não um espaço para viver. Um exemplo é o PRONAF, cuja meta é transformar o camponês tradicional em empreendedor rural. Provavelmente isso explica os movimentos migratórios, pois no meio rural o território é viabilizado pelo Estado para a reprodução do capital, que se apropria de espaços construídos por comunidades e campesinato tradicionais, que mantem com a terra uma relação de pertencimento, berço onde cultivam, criam, extraem e produzem as condições necessárias à produção de seu gênero de vida.

Busca-se nos territórios do dendê emprego e renda, abandona-se a unidade produtiva familiar, forma-se um campo sem camponeses, posto que 
estes se metamorfoseiam, paulatinamente, em trabalhadores para o capital (WANDERLEY, 2009). Esse movimento acentua processos anteriormente existentes nestes espaços rurais tais como a crise na produção familiar de alimentos, envelhecimento do agricultor familiar, enfraquecimento da pluriatividade, dependência e subordinação dos lugares à dinâmica das empresas, enfraquecimento dos movimentos sociais e das lutas pela reforma agrária, dentre outros que são objeto de investigação, análise e interpretação da geografia rural e dos movimentos sociais. Foge aos limites deste texto elucidar como, porque, quando e onde a dendeicultura aprofunda tais processos.

\section{CONSIDERAÇÕES FINAIS}

O espaço rural contém múltiplas possibilidades, sobretudo se concebido numa perspectiva territorial, consideradas a configuração espacial e as dinâmicas sociais que usam o espaço, territorializando ações. Espaço caracterizado pelo uso da terra, como principal força produtiva e meio de produção, por diferentes e divergentes grupos e classes sociais, uns concebendo-o eminentemente como setor produtivo da economia, outros como lugar singularizado por seu modo de vida, o campo é palco, produto e condicionante de lutas entre classes sociais para territorializar seus interesses, isto é, seus usos do território.

Em se tratando do espaço amazônico paraense, desconfiamos do boom do dendê que promete sustentabilidade ambiental, rentabilidade econômica, inclusão social de agricultores familiares, soberania e segurança energética e alimentar, sem que se esclareça para quem e como. Trata-se isto sim de mais um capítulo da questão agrária na Amazônia, onde as virtudes de um produto (drogas do sertão, borracha, manganês, ferro, bauxita, energia e gado) mostram-se insuficientes para assegurar espaços menos desiguais e mais justos. Forma-se isto sim verdadeiros processos de desenvolvimento de comunidades rurais, campos descampesinizados, espaços mais e mais esquizofrênicos, posto que organizados segundo comandos exógenos e não daqueles que cotidianamente os vivem.

A adesão aos projetos de agricultura familiar de dendê desencadeou mudanças na sua condição espacial. Na condição de agricultor camponês as necessidades da família determinavam o ritmo e a intensidade do trabalho no roçado. Igualmente a família comandava e controlava o processo produtivo. No lote do dendê, embora exista a presença do trabalho familiar, o comando e o controle da produção, bem como o ritmo do trabalho são determinados pela temporalidade do mercado mundial, que tem na empresa seu representante local. O agricultor integrado ao projeto não tem o uso do território, pois não 
decide sobre a natureza e a finalidade do trabalho, bom como da reprodução das relações de produção, não decide como e o quê plantar nas entrelinhas do dendê; tampouco pode escolher para quem vender sua produção e a que preço vender, porque estão "presos" pelas normas do contrato, do mercado e da empresa. Nessa condição, os agricultores apenas executam tarefas determinadas pela empresa, assemelhando-se a um trabalhador para o capital sem torná-lo um operário (WANDERLEY, 1985).

Os projetos de agricultura familiar do dendê manifestam o avanço da cultura com ritmo, finalidade e comando do trabalho dados pela comercialização do óleo de palma nos mercados de commodities. Tais projetos configuram-se como principais fontes de renda e reprodução das famílias, o que levou Nahum e Santos (2015) a sustentar que nos lugares em torno de onde se pratica a monocultura do dendê se reproduz um espaço rural sem camponês; mais que isso, os camponeses ao se integrarem aos projetos de agricultura familiar acentuam processos de descampesinização, tornando-se agricultores do dendê.

Muda-se a paisagem, a configuração espacial e a dinâmica social dos camponeses da comunidade do Arauaí e em torno. Esses lugares, tal como outros no município de Moju até o último quartel do século XX, eram marcados por sítios enquanto espaços da vida, unidade na diversidade de atividades e trabalho na rotina da roça, vivificada pela família ou mesmo pela solidariedade dos mutirões ritmados pelos ciclos naturais e neles os roçados de mandioca. Propagandeado como solução para a precariedade estrutural em que viviam os camponeses, o projeto de dendê familiar configura-se como estratégia do Estado brasileiro para que a empresa dendeicultura use o território, isto é, a área e a força de trabalho, sem que para isso tenha que adquirir terra e assalariar trabalhadores.

Ancorado num discurso de geração de emprego, renda e inclusão social, o projeto amplia a capacidade de consumo dos agricultores. O grande atrativo do projeto é que ele ampliar o poder de compra do agricultor integrado. Nesta situação emerge a enigmática figura do agricultor integrado à produção de dendê, que não é nem capitalista, pois que a lógica de sua unidade produtiva não é a reprodução do capital, nem é assalariado, posto que não é força de trabalho contratada pela empresa, tampouco continua camponês, visto que se alterou a natureza do trabalho, e, por conseguinte a paisagem, a configuração espacial, a dinâmicas social, enfim o território usado ou espaço geográfico enquanto quadro da sua vida. Lembrando Chayanov, podemos dizer que no lote de dendê o ritmo de trabalho não é definido pela equação trabalho versus necessidades camponesas. Longe disso, o calendário agrícola desenvolvido reduz o camponês à condição de produtor de fruto fresco colhido, matéria-prima sem qualquer 
valor agregado, atrativa tão somente pela voracidade do mercado de palma, pelas vantagens econômicas e técnicas oferecidas aos agricultores comparadas às demais culturas.

A dendeicultura não é a solução, nem é a causa dos males que afligem o espaço rural nas áreas antropizadas. É preciso superar a tradição política que subordina o desenvolvimento da Amazônia à ascensão e queda de um produto no mercado mundial, que deposita todas as esperanças ou mesmo amaldiçoa determinado produto; política que se regozija ao dizer "nossos minérios", "nossa floresta", "nossas riquezas" ou mesmo que repete o mito do desenvolvimento em muitos adjetivos, regional, sustentável, territorial, participativo. Esquecendo-se de perguntar quem usufrui das riquezas, sejam elas essências florestais, borracha, madeira, minérios, energia hidroelétrica e dendê. Dendê para quem? Dendê por quê? Dendê para quê?

Portanto, é preciso perguntar quem ganha com a dendeicultura, pois tão importante quanto ressaltar as potencialidades econômicas, ambientais e sociais do dendê, faz-se necessário refletir sobre quem usufrui dos dividendos dessas potencialidades, ou seja, quem fica com a renda da terra e se beneficia do território; refletir sobre os impactos no modo de vida do lugar onde o agronegócio do dendê se implanta e expande, isto é, sobre o que significa passar da condição de lavrador para agricultor de dendê ou de outro modo, de camponês tradicional para agricultor familiar do dendê, trabalhador para o capital.

\section{REFERÊNCIAS}

ABRAMOVAY, R. Paradigmas do capitalismo agrário em questão. São Paulo: Edusp, 2012.

ALTVATER, E. O fim do capitalismo como o conhecemos. Uma crítica radical do capitalismo. Rio de Janeiro: Civilização Brasileira, 2010.

ALVES, R. N. B.; CARDOSO, C. E. L. Sistemas e custos de produção de mandioca desenvolvidos por pequenos agricultores familiares do município de Moju, PA. Belém, Embrapa Amazônia Oriental. 2008.

AUBERTIN, Catherine (Org.). Fronteiras. Brasília: Editora da UNB, 1988.

BASA. "A experiência do Banco da Amazônia com projetos integrados de dendê familiar". Revista Contexto Amazônico. Ano 5, n. 22, 2012. Disponível em: http://www.bancoamazonia.com.br/images/arquivos/institucional/biblioteca/ boletim/contexto_amazonico_22.pdf. Acesso em: 04 mar. 2018. 
BERNSTEIN, H. Dinâmicas de classe da mudança agrária. São Paulo, Unesp, 2011.

BRASIL. Decreto n. 5.297, de 6 de dezembro de 2004, Dispõe sobre os coeficientes de redução das alíquotas da Contribuição para o PIS/PASEP e da COFINS [...]. Disponível em: http://www.planalto.gov.br/ccivil_03/_Ato2004-2006/2004/ Decreto/D5297.htm. Acesso em: 02 mar. 2018

CARDoso, F. H.; MÜLLER, G. Amazônia: expansão do capitalismo. Rio de Janeiro: Centro Edelstein de Pesquisas Sociais, 2008 .

CARVALHO, A. C. A. de C; NAHUM, J. S. Período do dendê na Amazônia paraense. In: NAHUM, J. S. (Org.). Dendeicultura e dinâmicas territoriais do espaço agrário na Amazônia Paraense. Belém: GAPTA/UFPA, 2014. p. 13-40.

CASTRO, A. M. G. de; LIMA, S. M. V; SILVA, J. F. V. Complexo Agroindustrial de Biodiesel no Brasil: competitividade das cadeias produtivas de matérias-primas. Brasília: Embrapa Agroenergia, 2010.

CHAUÍ, M. Cultura e democracia. São Paulo: Editora Cortez, 1990.

CHAYANOV, A. V. Sobre a teoria dos sistemas econômicos não capitalistas. In: SILVA, J. G.; STOLKE, V. (Org.). A questão agrária. São Paulo: Brasilense, 1981. p. $133-163$

CRUZ, B. E. V. da. Territorialização e organização espacial do Grupo Agropalma. 2006. Dissertação (Mestrado em Geografia) - Instituto de Filosofia e Ciências Humanas, Universidade Federal do Pará, Belém, 2006.

D'INCAO, M. A; SILVEIRA, I. M. da (Org.). A Amazônia e a crise da modernização. Belém: MPEG, 1994.

EMBRAPA. Zoneamento agroecológico do dendezeiro para as áreas desmatadas da Amazônia legal. Rio de Janeiro, Embrapa, 2010.

Embrapa Amazônia Oriental e o Agronegócio do Dendê no Pará.

Belém: Embrapa, 2006. Disponível em: https://www.embrapa.br/busca-depublicacoes/-/publicacao/394940/a-embrapa-amazonia-oriental-e-o-agronegociodo-dende-no-para Acesso em: 04 mar. 2018.

FURLAN, JÚNIOR et al. Biodiesel. Porque tem que ser dendê. Belém: EMBRAPA/ PALMASA, 2006.

GIDDENS, A. A política da mudança climática. Rio de Janeiro: Zahar Editora, 2010 .

HOUTART, F. A agroenergia. Solução para o clima ou saída da crise para o capital? Petrópolis: Vozes, 2010. 
LÉNA, P; OlIVEIRA, A. E. de. Amazônia. A fronteira agrícola 20 anos depois. Belém: CEJUP, 1992.

LIMA, S. M. V, CASTRO, A. M. G de. Agronegócio do biodiesel e suas matérias primas. In: CASTRO, A. M. G. de; LIMA, S. M. V; SILVA, J. F. V. (Org.). Complexo Agroindustrial de Biodiesel no Brasil: competitividade das cadeias produtivas de matérias-primas. Brasília: Embrapa Agroenergia. 2010. p. 47-112

MAPA. Anuário estatístico da agroenergia Brasília. 2010. Disponível em: http:/ / www.agricultura.gov.br/assuntos/sustentabilidade/agroenergia/pasta-anuarioestatistico-da-agroenergia/anuario-estatistico-da-agroenergia. Acesso em: 04 mar. 2018.

MARTINS, J de. S. Fronteira. A degradação do outro nos confins do humano. São Paulo: Editora HUCITEC, 1997.

MÜLLER, Antônio. A cultura do dendê. Belém, EMBRAPA-CPATU, 1980.

NAHUM, J. S. Região e representação: a Amazônia nos planos de Desenvolvimento. Biblio 3W revista bibliográfica de geografía y ciencias sociales, Universidad de Barcelona, v. XVII, n. 985, 2012. Disponível em: http://www.ub.edu/geocrit/b3w985.htm. Acesso em : 04 mar. 2018.

NAHUM, J. S; BASTOS, C. S. Dendeicultura e descampesinização na Amazônia paraense. Campo-Território: revista de geografia agrária, v. 9, n. 17, p. 469-485, abr. 2014. Disponível em: http://www.seer.ufu.br/index.php/campoterritorio/ issue/view/1113. Acesso em: 05 mar. 2018.

NAHUM, J. S; MALCHER, A. T. Dinâmicas territoriais do espaço agrário na Amazônia: a dendeicultura na microrregião de Tomé-Açu (PA). Confins [Online], v. 16, 2012. Disponível em: http://confins.revues.org/7947?lang=pt. Acesso em: 05 mar. 2018.

NAHUM, J. S.; SANTOS, C. B. Do sítio camponês ao lote de dendê: transformações do espaço rural na Amazônia paraense no século XXI. Revista NERA, Presidente Prudente-SP, v. 20, n. 37, p. 54-76, maio/ago. 2017. Disponível em: http://revista. fct.unesp.br/index.php/nera/issue/view/312. Acesso em: 05 mar. 2018.

O boom do dendê na microrregião de Tomé-Açu, na Amazônia paraense. Confins [Online], v. 25, nov. 2015. Disponível em: http://journals. openedition.org/confins/10536. Acesso em: 05 mar. 2018.

Impactos socioambientais da dendeicultura em comunidades tradicionais na Amazônia paraense. ACTA Geográfica, Boa Vista, Ed. Esp. Geografia Agrária, 2013. Disponível em: http://revista.ufrr.br/index.php/actageo/ issue/view/117/showToc. Acesso em : 05 mar. 2018. 
PINTO, G. Pompeu et al. Avaliação do projeto de agricultura familiar com dendê para fabricação de Biodiesel - Moju/PA, 2009. Monografia (Especialização em Produção de Biodiesel) - Universidade Federal do Pará/Universidade Federal Rural da Amazônia, Belém, 2009.

REPÓRTER BRASIL. Agricultura familiar e o programa nacional de Biodiesel: retrato do presente, perspectivas de futuro. Centro de Monitoramento de Agrocombustíveis, 2010. Disponível em: http://reporterbrasil.org.br/documentos/ AgriculturaFamiliar_Biodiesel2010.pdf. Acesso em: 05 mar. 2018.

RIVAL, A.; LEVANG, P. La palma de la controversia: La palma aceitera y los desafíos del desarrollo. Bogor, Indonesia: CIFOR, 2014.

SANTOS, C. B. Dendeicultura e comunidades tradicionais: uma análise do município de Moju. Belém: Itacaúnas, 2015.

SANTOS, M. A natureza do espaço. Técnica e tempo. Razão e emoção. São Paulo: Edusp, 2006.

SANTOS, M.; SILVEIRA, M. L. O Brasil. Território e sociedade no início do século XXI. São Paulo: Editora Record, 2001.

SEMEDO, I. O mercado de energia renovável: viabilidade econômica do dendê na agricultura familiar do Baixo Sul-Bahia. 2006. Dissertação (Mestrado em Economia) - Universidade Federal da Bahia, Salvador, 2006

SILVA, J. S de. Produtividade de óleo de palma na cultura do dendê na Amazônia oriental: influência do clima e do material genético. 2006. Dissertação (Mestrado em Fitotecnia) - Universidade Federal de Viçosa, Viçosa-MG, 2006.

SILVA, Maia, Ricardo Ramos da. Biodiesel no Brasil: análise de custo-benefício. Curitiba: Appris, 2015.

SMITH, A. A riqueza das nações. Investigação sobre sua natureza e suas causas. São Paulo: Editora Nova Cultural, 1996.

SUFRAMA/FGV. Potencialidades regionais. Estudo da viabilidade econômica do dendê. Manaus, 2003. Disponível em: http://www.suframa.gov.br/publicacoes/ proj_pot_regionais/dende.pdf. Acesso em: 05 jun. 2018.

WANDERLEY, M de. N. B. O mundo rural como um espaço de vida. Reflexões sobre a propriedade da terra, agricultura familiar e ruralidade. Porto Alegre: Editora da UFRGS, 2009.

O camponês: um trabalhador para o capital. Cadernos de Difusão de Tecnologia, Brasília, v. 2, n. 1, p. 13-78, jan./abr., 1985.

Texto submetido à Revista em 07.11.2016 Aceito para publicação em 27.09.2017 